\title{
NMR metabonomic study of lung cancer: metabolic profiling of urine and blood plasma
}

\author{
Joana Carrola1*, Cláudia M Rocha', António S Barros², Ana M Gil ${ }^{1}$, Brian J Goodfellow', Isabel M Carreira ${ }^{3}$, \\ João Bernardo ${ }^{4}$, Ana Gomes ${ }^{4}$, Vitor Sousa ${ }^{4,5}$, Lina Carvalho ${ }^{4,5}$, lola F Duarte ${ }^{1}$ \\ From 16th International Charles Heidelberger Symposium on Cancer Research \\ Coimbra, Portugal. 26-28 September 2010
}

Lung cancer is the leading cause of cancer death, its poor prognosis being related to asymptomatic development and late detection. Hence, there is great need for novel biomarkers that can aid in the early detection of lung cancer. In this study, NMR-metabonomics is applied for investigating lung cancer metabolic signatures in blood plasma and urine. Biofluid samples from lung cancer patients $(\mathrm{n}=73)$ and a control healthy group $(\mathrm{n}=56)$ were analysed by high resolution ${ }^{1} \mathrm{H}$ NMR $(500 \mathrm{MHz})$, and their spectral profiles subjected to multivariate statistics, namely Principal Component Analysis (PCA), Partial Least Squares Discriminant Analysis (PLS-DA) and Orthogonal Projections to Latent Structures (OPLS)-DA. Multivariate modelling of urinary spectral profiles allowed cancer and control groups to be clearly discriminated with sensitivity and specificity levels of 93 and 94\%, respectively. The metabolites giving rise to this separation were mainly creatinine, phenylacetylglycine and $\mathrm{N}$-acetylglutamine/glutamate (elevated in patients), and hippurate and trigonelline (reduced in patients relatively to controls). In the case of blood plasma, good discrimination between the two groups was also achieved, mainly due to increased levels of lactate and LDL+VLDL, and lower levels of HDL, glucose, acetate, histidine, glutamine and valine in cancer compared to healthy subjects. These results show the promising potential of NMR metabonomics for finding putative biomarkers of lung cancer in biofluids, collected in a minimally invasive way, which may have important diagnostic/prognostic impact.

* Correspondence: joanacarrola@ua.pt

${ }^{1}$ CICECO, Department of Chemistry, University of Aveiro, Aveiro, Portugal

Full list of author information is available at the end of the article

\section{Author details}

${ }^{1}$ CICECO, Department of Chemistry, University of Aveiro, Aveiro, Portugal. ${ }^{2}$ QOPNA, Department of Chemistry, University of Aveiro, Aveiro, Portugal. ${ }^{3}$ Cytogenetics Laboratory and CNC, Faculty of Medicine, University of Coimbra, Coimbra, Portugal. ${ }^{4}$ University Hospitals of Coimbra, Coimbra, Portugal. ${ }^{5}$ Institute of Pathological Anatomy, Faculty of Medicine, University of Coimbra, Coimbra, Portugal.

Published: 24 September 2010

\section{doi:}

Cite this article as: Carrola et al:: NMR metabonomic study of lung cancer: metabolic profiling of urine and blood plasma. BMC Proceedings 2010 4(Suppl 2):P67.
Submit your next manuscript to BioMed Central and take full advantage of:

- Convenient online submission

- Thorough peer review

- No space constraints or color figure charges

- Immediate publication on acceptance

- Inclusion in PubMed, CAS, Scopus and Google Scholar

- Research which is freely available for redistribution

Submit your manuscript at www.biomedcentral.com/submit
C Biomed Central 